\title{
Relato de Experiência: Os desafios da abordagem em mulheres recém diagnosticadas soropositivas
}

\author{
Bruna Santos Silva Barbosa de Magalhães, Ricardo Barros, Laura Lourenço
}

\begin{abstract}
Resumo
O acesso à saúde e a diagnósticos de doenças como o HIV vem sendo facilitado em demanda espontânea através do uso de testes rápidos. Desta forma, cria-se uma circunstância mais favorável para leitura do exame, ampliando o vínculo e garantindo uma atenção resolutiva para o cuidado da paciente. Descrever a importância de uma abordagem integral e cautelosa frente à mulher recém diagnosticada soropositiva e os desafios na adesão ao tratamento e estigma social na APS. Estudo de caso. Paciente 01, 37 anos, casada, com filho de 13 anos, comparece a Unidade desejando realizar o teste rápido de HIV. Seu marido a informou sobre contaminação após uma relação extraconjugal. Foi realizado no mesmo momento aconselhamento pré-teste e teste rápido que se apresentou positivo. A paciente se mostrou apreensiva, com inúmeros questionamentos sobre a vida, sua estrutura familiar e doença, neste primeiro contato foi realizada uma abordagem para melhor entendimento sobre o HIV, esclarecimentos da medicação, exames, meios de contaminação, fortalecimento de vínculo e adesão ao tratamento. Pactuado com a mesma uma continuidade de consultas mensais para o acompanhamento frente a esta realidade. Paciente 02, 22 anos, sem relação estável, comparece a unidade com suspeita de gravidez. Realizado TIG confirmatório, no mesmo momento é iniciado o pré-natal. Durante a consulta foi realizado aconselhamento pré-teste junto aos testes rápidos, HIV e VDRL. No pós-teste o resultado para HIV se apresentou positivo. Informação passada de forma cautelosa, gestante se apresentou abalada e confusa sendo realizado escuta ativa de seus anseios, orientações de tratamento, seguimento da gestação, encaminhamento para serviço de referência especializado e continuidade do cuidado. Compreende-se de fato as dificuldades de aceitação ao diagnóstico de HIV, devido a uma estigmatização social, associação a promiscuidade e carência de informações. Segundo o Ministério da Saúde, a adesão é um processo dinâmico e multifatorial que abrange aspectos físicos, psicológicos, sociais, culturais e comportamentais, e que requer decisões compartilhadas e corresponsabilizadas entre a pessoa que vive com HIV, a equipe de saúde e a rede social. Desta forma, se mostra mais evidente a necessidade de uma base de acompanhamento multiprofissional, em busca de estratégias para uma abordagem dinâmica, cautelosa, garantia de sigilo, encorajamento ao tratamento e qualidade de vida do portador do HIV.
\end{abstract}

Descritores: HIV; Mulheres; Enfermagem. 